(2) Open Access Full Text Article

\title{
Dietary Habit and Other Risk Factors of Chronic Kidney Disease Among Patients Attending Dessie Referral Hospital, Northeast Ethiopia
}

This article was published in the following Dove Press journal: International Journal of Nephrology and Renovascular Disease

\author{
Foziya Mohammed Hussien (D) \\ Hamid Yimam Hassen (iD) ${ }^{2}$ \\ 'Department of Public Health Nutrition, \\ School of Public Health, College of \\ Medicine and Health Science, Wollo \\ University, Dessie, Ethiopia; ${ }^{2}$ Department \\ of Primary and Interdisciplinary Care, \\ University of Antwerp, Antwerp, Belgium
}

Correspondence: Foziya Mohammed Hussien

Tel +25I 913714985

Email foziyamohammed2018@gmail.com
Background: In low- and middle-income countries, the burden of chronic kidney disease (CKD) is rising due to poor access to early detection and management services. In Ethiopia, little is known about the context-specific risk factors and their magnitude, particularly the dietary habit of patients is not studied. Therefore, this study aimed to identify the dietary and other risk factors of CKD in Northeast Ethiopia.

Methods: We conducted a facility-based unmatched case-control study utilizing quantitative method of data collection. Data were collected on a total of 66 cases and 134 controls using structured questionnaire and anthropometric measurements. Dietary habit was assessed using the Diet History Questionnaire (DHQ). Medical history, patient chart review and physical examination were employed to collect other relevant information. To identify independent predictors of CKD, we conducted a multivariable logistic regression analysis.

Results: About $54.5 \%$ cases and $46.3 \%$ of controls were female, while $40.9 \%$ of cases and $38.8 \%$ of controls were within the age group of 36-55. All cases and 128 (95.5\%) controls consumed meat in the last year. Forty-six (69.7\%) cases and $74(55.2 \%)$ controls use palm oil as the main cooking oil. History of hypertension (adjusted odds ratio $(\mathrm{AOR})=2.39 ; 95 \% \mathrm{CI}$ : 1.17-4.89), anemia ( $\mathrm{AOR}=2.38$; 95\%CI: 1.04-5.42), palm oil use $(\mathrm{AOR}=2.10 ; 95 \% \mathrm{CI}$ : $1.01-4.35)$ and family history of $\mathrm{CKD}(\mathrm{AOR}=8.77$; 95\%CI: 3.73-20.63) were significantly associated with the risk of having CKD.

Conclusion: Meat consumption and use of palm oil are higher among patients with CKD than controls. History of hypertension, anemia, family history of CKD and palm oil consumption were found to be risk factors for CKD. Dietary counseling interventions and dietary modifications might help in CKD prevention. Furthermore, routine urinalysis and estimation of glomerular filtration rate (GFR) for all hospitalized patients with hypertension and anemia could help to detect CKD at an earlier stage for a better prognosis.

Keywords: chronic kidney disease, diet, hypertension, anemia, cooking oil

\section{Introduction}

The rapid rise in the burden of chronic noncommunicable diseases (NCDs) is leading to extensive social, economic, and health consequences, particularly in low- and middle-income countries (LMICs). According to the World Health Organization (WHO) report, NCDs kill 41 million people each year worldwide, equivalent to $71 \%$ of all deaths. ${ }^{1}$ In 2012 , the major NCDs accounted for 38 million $(68 \%)$ of the world's total deaths, more than $40 \%$ of them were premature deaths under age of 70 years. ${ }^{2}$ Due to rapid urbanization, demographic 
transition, lifestyle change, and increase in population aging, the burden of NCDs is rising in LMICs. ${ }^{3}$ Almost three-quarters of all NCD deaths, and the majority of premature deaths $(82 \%)$, occur in LMICs. ${ }^{2,4,5}$ According to the World Economic Forum, NCD such as cardiovascular diseases (CVDs) and diseases of the kidney, are a severe threat to global economic development due to the long-term costs of treatment and the negative effects on population productivity.,

As in any other NCDs, chronic kidney diseases (CKDs) are also among the growing public health problem, with a $9 \%$ annual increase in the number of patients worldwide. ${ }^{7}$ A meta-analysis on 44 countries estimated the worldwide prevalence of CKD to be $13.4 \%$ (95\%CI: $11.7-15.1 \%){ }^{8}$ Similarly, the most recent Global Burden of Diseases (GBD) study indicated the prevalence of CKD worldwide estimated to be $9.1 \%$, and it caused 1.2 million deaths in 2017. ${ }^{9}$ The prevalence is estimated to be $15 \%$ higher in LMICs compared with high-income countries. ${ }^{10} \mathrm{CKD}$ is associated with an increase in CVD and premature mortality, with detrimental societal and economic challenges. ${ }^{11-13}$

Studies have shown behavioral factors such as smoking, physical inactivity, unhealthy dietary pattern, and alcohol consumption are related with CKD. ${ }^{14-16}$ Furthermore, overweight, high blood pressure, diabetes, and anemia are also associated with higher risk of CKD. ${ }^{14,17}$ Socioeconomic factors such as older age, lower income and gender are also considered as distal risk factors. ${ }^{14,18}$

In 2013, the World Health Assembly endorsed a set of actions organized to prevent and control noncommunicable diseases between 2013 and 2020, which will help to achieve national and international goals set by countries. $^{2,19}$ Despite the presence of goals and action plans, NCDs including CKD are continuing to be the most important public health problem, particularly in LMICs. This could be attributed to poor community awareness, higher prevalence of risk factors, and poor access to screening services. Early detection and treatment can prevent or minimize complications associated with $\mathrm{CKD} ;{ }^{20}$ however, the majority of CKD cases might not be recognized early because of the patients' lack of awareness about CKD and associated risk factors. ${ }^{21}$ In LMICs, prevention and control strategies are limited due to inadequacy of evidence on contextual risk factors. In Ethiopia, the magnitude and risk factors of CKD are not well studied. Hence, the present study aimed to identify the dietary and other risk factors of CKD in Northeast Ethiopia.

\section{Materials and Methods}

\section{Study Setting, Design and Participants}

We conducted a facility-based unmatched case-control study in Dessie referral hospital, Northeast Ethiopia, from April to May 2019. The hospital was established in 1962 and currently provides a service to an average of 800,000 patients annually. The cases were all patients with confirmed CKDs who had followup in Dessie referral hospital, whereas controls were outpatients who were attending the same hospital during the study period and confirmed as not having CKD. CKD was defined as glomerular filtration rate $($ GFR $)<60 \mathrm{~mL} / \mathrm{min} / 1.73 \mathrm{~m}^{2}$ for $>3$ months. ${ }^{22}$ CKD patients aged $\geq 18$ years with a minimum of two creatinine records were included. Critically ill patients and pregnant women were excluded. The sample size (68 cases and 134 controls) for the study was determined using Epi Info version 7.1 (Center for Disease Control and Prevention, Atlanta, Georgia), assuming a 54.8 percentage of risk factors among controls (obesity), ${ }^{23}$ a $2.75 \mathrm{OR}$, a $95 \% \mathrm{CI}$, an $80 \%$ power, and an expectation of $10 \%$ nonresponse rate. Cases and controls were selected randomly.

\section{Data Collection and Quality Control}

Data were collected using the Open Data Kit (ODK) (Apache Software Foundation, Forest Hill, Maryland) platform. We collected information on socioeconomic status including education and occupation, self-reported personal and family history of chronic diseases using a structured questionnaire. To assess the dietary habit of individuals, the Diet History Questionnaire (DHQ) was adapted from the National Institute of Health, Epidemiology and Genetics research program. ${ }^{24}$ It was used to ascertain the usual dietary intake one year prior to data collection and included staple foods and beverages grouped into 11 sections: (1) cereals; (2) legumes, nuts and seeds; (3) vegetables; (4) fruits; (5) organ and flesh meat; (6) fish; (7) milk and dairy products; (8) eggs; (9) oils and fats; (10) sweets; and (11) spices, condiments, beverages. For each food group, cases and controls were asked to describe the frequency (per day, per week, per month and per year) they consumed each specific food group. All foods consumed inside or outside the home, no matter where they were prepared were included. Very small food quantities less than one tablespoon were excluded. Each food group had dichotomous yes/no responses with the subsequent frequency of consumption. 
In addition, the type of cooking oil was assessed and dichotomized in to either palm or liquid oil by showing the picture of commonly used brands. Trained data collectors captured the dietary data.

Height was taken using a stadiometer when the respondent was standing straight and without shoes. The readings were taken at the apex of the head with $0.1 \mathrm{~cm}$ precision. ${ }^{25}$ Weight was taken using Seca digital weighting scale and subjects were requested to remove footwear, heavy clothes and heavy items from their pockets. Measurements were taken to $0.1 \mathrm{~kg}$ precision. All measurements were taken twice and the average was recorded. ${ }^{26}$ Body mass index (BMI) was calculated by dividing weight in kilograms $(\mathrm{kg})$ by height in meters $(\mathrm{m})$ squared $(\mathrm{BMI}=\mathrm{kg} / \mathrm{m} 2){ }^{22}$ Two blood pressure readings were taken from right arm using a manual sphygmomanometer after the participant had remained in a seated position for five minutes with his or her arm resting on the chair.

To identify controls we used a standard phlebotomy procedures and drew $5 \mathrm{~mL}$ of whole blood from an antecubital vein into dry tubes for serum creatinine test and collect $10 \mathrm{~mL}$ urine for urinalysis. Plasma creatinine was measured by enzymatic colorimetric assay using Olympus AU 640 (Southend-on-Sea, United Kingdom). Chronic Kidney Disease Epidemiology Collaboration (CKD EPI) equation was used to calculate estimated GFR. Assay variation was checked daily with an internal quality assessment scheme, and the coefficient of variation for each test to be below $5 \%$.

To control the data quality, three days training was given for all data collectors on interviewing technique, sample collection and handling by medical doctors and senior nurses. Supervisors monitored data collection process daily and the principal investigator visited the data collection frequently. Ten percent of the questionnaire was pretested among similar patients in Woldiya Hospital. Internal consistency was checked until Cronbach's alpha 0.7 was reached. Completeness and consistency of the collected data were checked during data collection. Anthropometric equipment was calibrated after every measurement to control fallacy. Both intra-observer and interobserver variation were checked during training of anthropometric measurement and the training continued until the coefficient of variation less than $3 \%$ was reached. All laboratory instruments were calibrated to improve sample quality and reliability. Laboratory tests were done according to manufacturer's instructions.

\section{Data Analysis}

The collected data using ODK were downloaded from the server in the form of CSV file, then exported to the Statistical Package for Social Sciences (SPSS) software version 23.0 (IBM Corporation, Armonk, NY, USA) for further processing and analysis. Descriptive summaries, including frequencies, proportions and cross-tabulations were used to present study results. For continuous variables, mean with SD or median with IQR were computed. Bivariable logistic regression was used to assess the crude association between variables and CKD and to identify variables for consideration in the multivariable model. Those variable with $P$-value $<0.3$ were included to multivariable logistic regression. To identify dietary and other predictors of CKD, multivariable analysis was performed using binary logistic regression. Model fit was checked using Hosmer and Lemeshow goodness of fit test. Finally, predictors with a $P$-value $<0.05$ were considered statistically significant and OR with $95 \% \mathrm{CI}$ were used to describe the association.

\section{Results}

\section{Sociodemographic Characteristics of Participants}

A total of 200 adults 66 cases and 134 controls were enrolled into the study, making the response rate $99 \%$ and $100 \%$ respectively. Of which, $36(54.5 \%)$ cases and $62(46.3 \%)$ of controls were female. The mean age of participants was 50.9 years (SD: 16.5) and 46 (SD: 16.3) for cases and controls respectively. Twenty-seven (40.9\%) cases and $52(38.8 \%)$ controls were within the age group of 36 to 55 years. The average family size was 5.1 (SD: $2.1)$ and 4.5 (SD: 2.2) persons per household among cases and controls respectively. Above three-quarters (75.8\%) of cases and $96(71.6 \%)$ controls were married, while $6(9.1 \%)$ cases and $21(15.7 \%)$ controls were single. More than one-fifth $14(21.2 \%)$ and 29 (21.6\%) cases and controls respectively, were unable to read and write. The majority $83.3 \%$ of cases and 102 (76.1\%) controls reported average monthly income above 1001 Ethiopian Birr ( 31.3USD) per month. (Table 1)

\section{Dietary History of Study Participants}

All cases and controls consumed a cereal based diet within one year prior to data collection, of which $41(62.1 \%)$ and $99(73.3 \%)$ cases and controls respectively, ate three or more times a day. All cases and controls consumed 
Table I Sociodemographic Characteristics of the Study Participants in Dessie Referral Hospital, 2019

\begin{tabular}{|c|c|c|c|c|}
\hline Variables & Category & Cases N (\%) & Controls N (\%) & $\boldsymbol{P}$-value \\
\hline Sex & $\begin{array}{l}\text { Male } \\
\text { Female }\end{array}$ & $\begin{array}{l}30(45.5) \\
36(54.5)\end{array}$ & $\begin{array}{l}72(53.7) \\
62(46.3)\end{array}$ & 0.27 \\
\hline Age (years) & $\begin{array}{l}18-35 \\
36-55 \\
56+\end{array}$ & $\begin{array}{l}14(2 \mid .2) \\
27(40.9) \\
25(37.9)\end{array}$ & $\begin{array}{l}42(31.3) \\
52(38.8) \\
40(29.9)\end{array}$ & 0.28 \\
\hline Marital status & $\begin{array}{l}\text { Single } \\
\text { Married } \\
\text { Divorced } \\
\text { Widowed }\end{array}$ & $\begin{array}{l}6(9.1) \\
50(75.8) \\
4(6.1) \\
6(9.1)\end{array}$ & $\begin{array}{l}21(15.7) \\
96(71.6) \\
8(6) \\
9(6.7)\end{array}$ & 0.60 \\
\hline Educational status & $\begin{array}{l}\text { Cannot read and write } \\
\text { Primary education }(I-8) \\
\text { Secondary education }(9-\mid 2) \\
\text { Tertiary education }(>\mid 2)\end{array}$ & $\begin{array}{l}14(21.2) \\
20(30.3) \\
15(22.7) \\
17(25.8)\end{array}$ & $\begin{array}{l}29(21.6) \\
55(4 I) \\
19(14.2) \\
31(23.1)\end{array}$ & 0.34 \\
\hline Monthly household income & $\begin{array}{l}\leq 500 \\
501-1000 \\
1001+\end{array}$ & $\begin{array}{l}4(6.1) \\
7(10.6) \\
55(83.3)\end{array}$ & $\begin{array}{l}6(4.5) \\
26(19.4) \\
102(76.1)\end{array}$ & 0.27 \\
\hline
\end{tabular}

legumes and nuts, of which $28(42.4 \%)$ cases and 76 (56.7\%) controls consumed once to twice a day. All cases and controls consumed vegetables within a year before the study, among them 11 (16.7\%) cases and 26 (16.9\%) controls consumed vegetables twice per week. About 65 (98.5\%) cases and 120 (89.6\%) controls consumed fruits within a year before the study, of which 19 (28.8\%) and 14 (10.4\%) cases and controls respectively, consumed two to three times per month.

All cases and 128 (95.5\%) controls consumed meat, whereas 21 (31.8\%) cases and 39 (29.1\%) controls consumed fish within a year before the study, of which 12 $(18.2 \%)$ cases and $24(17.9 \%)$ controls consumed meat once per month, and eight (12.1\%) cases and 11 (8.2\%) controls consumed fish one to six times per year. More than two thirds 57 (86.4\%) of cases and 125 (93.3\%) controls consumed milk, of which $13(19.7 \%)$ cases and $17(12.7 \%)$ controls consumed two to three times per month. Fifty-six (84.8\%) cases and $109(81.3 \%)$ controls consumed egg, of which $10(15.2 \%)$ and $25(18.7 \%)$ cases and controls consumed two to three times per month. Nearly all 64 (97\%) cases and $123(91.8 \%)$ controls consumed condiments and beverages within a year before the study, of which $24(36.4 \%)$ cases and 59 (44\%) controls consumed once to twice daily. (Table 2)

About 65 (98.5\%) cases and 132 (98.5\%) controls have consumed oils and fats, of which $15(22.7 \%)$ and 60
(44.8\%) cases and controls consumed three or more times per day respectively. About $46(69.7 \%)$ cases and $74(55.2 \%)$ controls use solid (palm) oil as the main cooking oil. More than half $(63.6 \%)$ cases and 81 $(60.4 \%)$ controls consumed sugary foods, among them

Table 2 Dietary History of CKD Patients and Controls One Year Before the Study Period in Dessie Referral Hospital, 2019

\begin{tabular}{|c|c|c|c|}
\hline Variables & Category & $\begin{array}{l}\text { Cases } \\
\mathbf{N}(\%)\end{array}$ & $\begin{array}{l}\text { Controls } \\
\mathbf{N}(\%)\end{array}$ \\
\hline $\begin{array}{l}\text { Vegetable } \\
\text { consumption }\end{array}$ & $\begin{array}{l}\text { Yes } \\
\text { No }\end{array}$ & $\begin{array}{l}66(100) \\
0\end{array}$ & $\begin{array}{l}134(100) \\
0\end{array}$ \\
\hline Fruit consumption & $\begin{array}{l}\text { Yes } \\
\text { No }\end{array}$ & $\begin{array}{l}65(98.5) \\
\text { I (I.5) }\end{array}$ & $\begin{array}{l}120(89.6) \\
14(10.4)\end{array}$ \\
\hline Meat consumption & $\begin{array}{l}\text { Yes } \\
\text { No }\end{array}$ & $\begin{array}{l}66(100) \\
0\end{array}$ & $\begin{array}{l}128(95.5) \\
6(4.5)\end{array}$ \\
\hline Fish consumption & $\begin{array}{l}\text { Yes } \\
\text { No }\end{array}$ & $\begin{array}{l}21(31.8) \\
45(68.2)\end{array}$ & $\begin{array}{l}39(29.1) \\
95(70.9)\end{array}$ \\
\hline Milk consumption & $\begin{array}{l}\text { Yes } \\
\text { No }\end{array}$ & $\begin{array}{l}57(86.4) \\
9(13.6)\end{array}$ & $\begin{array}{l}125(93.3) \\
9(6.7)\end{array}$ \\
\hline Egg consumption & $\begin{array}{l}\text { Yes } \\
\text { No }\end{array}$ & $\begin{array}{l}56(84.8) \\
10(15.2)\end{array}$ & $\begin{array}{l}109(81.3) \\
25(18.7)\end{array}$ \\
\hline $\begin{array}{l}\text { Condiments } \\
\text { consumption }\end{array}$ & $\begin{array}{l}\text { Yes } \\
\text { No }\end{array}$ & $\begin{array}{l}64(97) \\
2(3)\end{array}$ & $\begin{array}{l}123(91.8) \\
\text { II (8.2) }\end{array}$ \\
\hline Total & & 66 & 134 \\
\hline
\end{tabular}


$19(28.8 \%)$ cases and $11(8.2 \%)$ controls have consumed seven to eleven times per year.

\section{Anthropometric Data and Medical Conditions}

About 11 (16.7\%) cases and 30 (22.4\%) controls were overweight, while none of the cases and nine $(6.7 \%)$ controls were underweight. Thirty-six (54.5\%) cases and 46 (34.3\%) controls, and $32(48.5 \%)$ cases and $55(41.0 \%)$ controls had history of hypertension and diabetes mellitus respectively. Twenty-four (36.4\%) cases and 20 (14.9\%) controls, and 4 (6.1\%) cases and 13 (9.7\%) controls had a history of anemia and tuberculosis respectively. More than one-tenth (12.1\%) of cases and $10(7.5 \%)$ controls had a history of osteoporosis. None of the cases and controls had a history of cancer and chemotherapy for cancer treatment. Twenty-nine (43.9\%) cases and $10(7.5 \%)$ controls had a family history of kidney disease. Forty-one (62.1\%) cases and $70(52.2 \%)$ controls, and $16(24.2 \%)$ cases and $25(18.7 \%)$ controls took antiinflammatory drug and herbal medication respectively, within a year before the study period (Table 3 ).

Table 3 Medical Conditions and Nutritional Status of Study Participants in Dessie Referral Hospital, 2019

\begin{tabular}{|c|c|c|c|}
\hline Variables & Category & $\begin{array}{l}\text { Cases } \\
\text { N (\%) }\end{array}$ & $\begin{array}{l}\text { Controls } \\
\mathbf{N}(\%)\end{array}$ \\
\hline Hypertension & $\begin{array}{l}\text { Yes } \\
\text { No }\end{array}$ & $\begin{array}{l}36(54.5) \\
30(45.5)\end{array}$ & $\begin{array}{l}46(34.3) \\
88(65.7)\end{array}$ \\
\hline Diabetes mellitus & $\begin{array}{l}\text { Yes } \\
\text { No }\end{array}$ & $\begin{array}{l}32(48.5) \\
34(51.5)\end{array}$ & $\begin{array}{l}55(41.0) \\
79(59.0)\end{array}$ \\
\hline Anemia & $\begin{array}{l}\text { Yes } \\
\text { No }\end{array}$ & $\begin{array}{l}24(36.4) \\
42(63.6)\end{array}$ & $\begin{array}{l}20(14.9) \\
114(85.1)\end{array}$ \\
\hline Tuberculosis & $\begin{array}{l}\text { Yes } \\
\text { No }\end{array}$ & $\begin{array}{l}4(6.1) \\
62(93.9)\end{array}$ & $\begin{array}{l}13(9.7) \\
121(90.3)\end{array}$ \\
\hline Osteoporosis & $\begin{array}{l}\text { Yes } \\
\text { No }\end{array}$ & $\begin{array}{l}8(12.1) \\
58(87.9)\end{array}$ & $\begin{array}{l}10(7.5) \\
124(92.5)\end{array}$ \\
\hline Cancer & $\begin{array}{l}\text { Yes } \\
\text { No }\end{array}$ & $\begin{array}{l}0 \\
66(100)\end{array}$ & $\begin{array}{l}0 \\
134(100)\end{array}$ \\
\hline $\begin{array}{l}\text { Use of anti- } \\
\text { inflammatory drug }\end{array}$ & $\begin{array}{l}\text { Yes } \\
\text { No }\end{array}$ & $\begin{array}{l}41(62.1) \\
25(37.9)\end{array}$ & $\begin{array}{l}70(52.2) \\
64(47.8)\end{array}$ \\
\hline Nutritional status & $\begin{array}{l}\text { Underweight } \\
\text { Normal } \\
\text { Overweight }\end{array}$ & $\begin{array}{l}0 \\
55(83.3) \\
11(16.7)\end{array}$ & $\begin{array}{l}9(6.7) \\
95(70.9) \\
30(22.4)\end{array}$ \\
\hline Total & & 66 & 134 \\
\hline
\end{tabular}

\section{Risk Factors of Chronic Kidney Disease}

Among seven variables entered to the multivariable logistic regression, four variables were significantly associated with CKD. The odds of having CKD are 2.4 times higher for patients who have a history of hypertension than nonhypertensive patients (AOR=2.39; 95\%CI: 1.17-4.89). Similarly, the odds of having CKD is 2.1 times higher for patients who use palm oil compared with those who consume vegetable oil $(\mathrm{AOR}=2.10 ; 95 \% \mathrm{CI}: 1.01-4.35)$. Furthermore, the odds of CKD are 8.8 times higher for individuals who have a family history of kidney disease than those with no family history of kidney disease (AOR=8.77; 95\%CI: 3.73-20.63). Individuals who had a history of anemia have 2.4 times higher odds of having CKD than those without a history of anemia $(\mathrm{AOR}=2.38 ; 95 \% \mathrm{CI}$ : 1.04-5.42) (Table 4).

\section{Discussion}

In this study, we found that the majority of cases and controls consume cereals three or four times per day. Higher consumption of meat and palm oil use was observed among cases than controls. A higher proportion of anemia and family history of CKD was observed among cases than controls. Moreover, this study identified palm oil use, hypertension, anemia and family history of CKD were significantly associated with a higher likelihood of CKD.

All cases and controls consumed a cereal-based diet within a year prior to the study; most of them eat three or more times daily. A study by $\mathrm{Hu}$ et al indicated higher consumption of carbohydrate diet is a risk for renal diseases, ${ }^{27}$ this can be due to excess consumption of cereal-based diet resulting in obesity, which promotes a decrease in GFR and an increase in proteinuria. ${ }^{28}$ All cases and controls consumed legumes and nuts within a year, the majority consumed one or two times daily.

In our study, meat consumption is higher among cases than controls, which is coherent with a meta-analysis of case-control studies, which showed high intake of meat and red meat as a risk for renal disease. ${ }^{29,30}$ This could be due to high meat protein intakes resulting in increased dietary acid loads and compensatory increases in renal acid excretion and ammonia production, leading to metabolic acidosis with a higher risk for tubulointerstitial injury. ${ }^{31}$ Restricted protein intake is therefore recommended for the prevention of kidney damage. ${ }^{32}$

In this study, lower consumption of milk was observed among cases than controls, which is coherent with a study conducted by Gopinath et al that reported dairy products have 
Table 4 Risk Factors of CKD in Dessie Referral Hospital, 2019

\begin{tabular}{|c|c|c|c|c|c|}
\hline \multirow[t]{2}{*}{ Variables } & \multirow[t]{2}{*}{ Category } & \multicolumn{2}{|c|}{ Chronic Kidney Disease } & \multirow[t]{2}{*}{ COR $(95 \% \mathrm{Cl})$} & \multirow[t]{2}{*}{ AOR $(95 \% \mathrm{Cl})$} \\
\hline & & Yes & No & & \\
\hline Hypertension & $\begin{array}{l}\text { Yes } \\
\text { No }\end{array}$ & $\begin{array}{l}36 \\
30\end{array}$ & $\begin{array}{l}46 \\
88\end{array}$ & $\begin{array}{l}2.29(1.26-4.19) \\
1\end{array}$ & $\begin{array}{l}2.39(1.17-4.89)^{*} \\
\text { । }\end{array}$ \\
\hline Family history of CKD & $\begin{array}{l}\text { Yes } \\
\text { No }\end{array}$ & $\begin{array}{l}29 \\
37\end{array}$ & $\begin{array}{l}10 \\
124\end{array}$ & $\begin{array}{l}9.71(4.33-21.78) \\
\text { I }\end{array}$ & $\begin{array}{l}8.77(3.73-20.63)^{* * *} \\
\mathrm{I}\end{array}$ \\
\hline Type of oil use & $\begin{array}{l}\text { Solid } \\
\text { Liquid }\end{array}$ & $\begin{array}{l}46 \\
20\end{array}$ & $\begin{array}{l}74 \\
60\end{array}$ & $\begin{array}{l}\mathrm{I} .87(0.99-3.49) \\
\mathrm{I}\end{array}$ & $\begin{array}{l}2.10(1.01-4.35)^{*} \\
1\end{array}$ \\
\hline History of anemia & $\begin{array}{l}\text { Yes } \\
\text { No }\end{array}$ & $\begin{array}{l}24 \\
42\end{array}$ & $\begin{array}{l}20 \\
114\end{array}$ & $\begin{array}{l}3.26(1.63-6.49) \\
1\end{array}$ & $\begin{array}{l}2.38(1.04-5.42)^{*} \\
1\end{array}$ \\
\hline Diabetes mellitus & $\begin{array}{l}\text { Yes } \\
\text { No }\end{array}$ & $\begin{array}{l}32 \\
34\end{array}$ & $\begin{array}{l}55 \\
79\end{array}$ & $\begin{array}{l}\text { I.35 (0.74-2.44) } \\
\text { I }\end{array}$ & $\begin{array}{l}0.90(0.42-1.90) \\
1\end{array}$ \\
\hline Taking anti-inflammatory drug & $\begin{array}{l}\text { Yes } \\
\text { No }\end{array}$ & $\begin{array}{l}41 \\
25\end{array}$ & $\begin{array}{l}70 \\
64\end{array}$ & $\begin{array}{l}\text { I.49 }(0.82-2.73) \\
\mathrm{I}\end{array}$ & $\begin{array}{l}\text { I.2I (0.59-2.49) } \\
\mathrm{I}\end{array}$ \\
\hline Age & $\begin{array}{l}18-35 \\
36-55 \\
\geq 56\end{array}$ & $\begin{array}{l}14 \\
27 \\
25\end{array}$ & $\begin{array}{l}42 \\
52 \\
40\end{array}$ & $\begin{array}{l}\text { I } \\
\text { I.56 (0.73-3.34) } \\
\text { I.88 (0.86-4.II) }\end{array}$ & $\begin{array}{l}\text { I } \\
\text { I.67 (0.65-4.24) } \\
2.17(0.79-5.92)\end{array}$ \\
\hline
\end{tabular}

Note: Statistically significant at $* P<0.05, * * P<0.01$.

Abbreviations: COR, crude odds ratio; AOR, adjusted odds ratio; BMI, body mass index; CKD, chronic kidney disease; CKD EPI, Chronic Kidney Disease Epidemiology Collaboration; CVD, cardiovascular disease; GFR, glomerular filtration rate; LMICs, low- and middle-income countries; NCD, non-communicable disease; ODK, Open Data Kit.

a protective effect on $\mathrm{CKD} .^{33}$ The possible reason might be the anti-inflammatory properties of dairy foods that subsequently decrease oxidative stress and renal damage. ${ }^{34,35}$

In our study, the risk of having CKD was higher among those with a history of hypertension than those who do not have. This finding is consistent with several related studies, ${ }^{23,36-38}$ which reported hypertension as the main risk factor of CKD. This could be due to the kidney being unable to function properly unless adequately perfused with intact blood stream. Unless detected and treated early, hypertension might lead to fatal consequences such as stroke and renal failure stroke. Thus, GFR and albuminuria should be determined for hypertensive patients at a regular interval for earlier detection of CKD to take appropriate measures accordingly. Then using antihypertensive agents regularly and controlling blood pressure (BP) is essential for hypertension patients to reduce the rate of progression to renal damage.

The present study indicated that consumption of palm oil is associated with high risk of CKD. This finding is in line with various studies that reported individuals who consumed mostly saturated fat were deemed to have a higher risk of reduced renal function, and those with higher levels of high density lipoprotein (HDL) cholesterol were associated with a lower risk for CKD. ${ }^{39-42}$ Thus, reducing the consumption of palm oil and replacing with vegetable oil could help in the prevention of the disease. Dietary counseling for patients with CKD who are under follow-up could help to slow progression of the diseases and prevent associated premature mortality. ${ }^{42,43}$

Our study also found that a family history of kidney disease is associated with higher risk of CKD, which is supported by studies done in Debre Berhan referral hospital and Southern Ethiopia. ${ }^{43,44}$ This finding necessitate routine urinalysis and estimation of GFR for all hospitalized patients who had a family history of kidney disease, and assessing family history of kidney disease in patients with renal complaint is essential. Furthermore, individuals who had a family history of kidney disease should develop a habit of hospital visits for routine kidney checkups.

This study found, the odds of having CKD is higher among patients with a history of anemia. Several studies found higher prevalence of anemia among patients with CKD and the prevalence increased with worsening kidney function. ${ }^{38,45,46}$ Several mechanisms of anemia have been indicated; including decreased red cell life span, abnormal iron metabolism, chronic inflammation, and metabolic abnormalities. $^{47-50}$ Therefore, routine hemoglobin and 
hematocrit checkups, and iron supplementation should be considered for patients with CKD to improve quality of life, reduce disease progression and mortality.

The present study should be interpreted considering the following limitations. Firstly, it considers food groups instead of food items, and the actual intake of food and nutrients were not estimated and weighed. Secondly, the effect size of family history of CKD has a wide confidence interval, which indicates less precision. However, it remains significant and the lower bound of $95 \% \mathrm{CI}$ is high, showing it is an important risk factor.

\section{Conclusion}

Our study found that higher consumption of meat, cereal based diet and palm oil is observed among CKD cases than controls, so nutritional counseling and dietary modification plays an important role in prevention of CKD. Hypertension, family history of CKD, and palm oil use were found to be risk factors of CKD. Moreover, higher prevalence of anemia observed among CKD patients than their counter controls. Thus, emphasis should be given for hypertensive, anemic and individuals with a family history of CKD in routine urinalysis and GFR estimation, and risk management services for better prognosis.

\section{Data Sharing Statement}

It is available based on request.

\section{Ethical Consideration}

Ethical approval was obtained from the Institutional Review Board of Wollo University, College of Medicine and Health Sciences. Written consent was obtained from each participant after explanation of the study purpose, description of possible risks and benefits. The study is in compliance with the principles of the Declaration of Helsinki. Privacy and confidentiality of the collected information were ensured throughout the process; measures were taken to ensure respect, dignity, and freedom of each individual participating in the study. All information gained during the study was kept strictly confidential.

\section{Acknowledgments}

The authors would like to thank Wollo University Research Coordinating Office for providing the opportunity to carry out this research. Finally, we want to express our gratitude to all subjects included in the study for their willingness to participate.

\section{Author Contributions}

Both authors (FMH and HYH) made substantial contributions to the conception and design, acquisition of data, or analysis and interpretation of data; took part in drafting the article or revising it critically for important intellectual content; gave final approval of the version to be published; and agree to be accountable for all aspects of the work.

\section{Disclosure}

Authors declare that they have no competing interests.

\section{References}

1. WHO. Noncommunicable diseases. 2018 Available from: https:// www.who.int/news-room/factsheets/detail/noncommunicable-dis eases. Accessed May 1, 2020.

2. WHO. GLOBAL STATUS REPORT on noncommunicable diseases. 2014.

3. Alwan A, MacLean DR, Riley LM, et al. Monitoring and surveillance of chronic non-communicable diseases progress and capacity in high-burden countries. Lancet. 2010;376(9755):1861-1868. doi:10. 1016/S0140-6736(10)61853-3

4. El Minshawy O. End-stage renal disease in the El-Minia governorate, upper Egypt: an epidemiological study. Saudi J Kidney Dis Transpl. 2011;22(5):1048-1054.

5. Moura LD, Prestes IV, Duncan BB, et al. Construção de base de dados nacional de pacientes em tratamento dialítico no Sistema Único de Saúde, 2000-2012. Epidemiol Serv Saude. 2014;23 (2):227-238. doi:10.5123/S1679-49742014000200004

6. Bloom DE, Cafiero E, Jané-Llopis E, et al. The Global Economic Burden of Non-Communicable Diseases. Geneva: World Economic Forum; 2011.

7. Barsoum RS. Chronic kidney disease in the developing world. $N$ Engl J Med. 2006;354(10):997-999. doi:10.1056/NEJMp058318

8. Hill NR, Fatoba ST, Oke JL, et al. Global prevalence of chronic kidney disease - a systematic review and meta-analysis. PLoS One. 2016;11(7):e0158765. doi:10.1371/journal.pone.0158765

9. Bikbov B, Purcell CA, Levey AS, et al. Global, regional, and national burden of chronic kidney disease, 1990-2017: a systematic analysis for the Global Burden of Disease Study 2017. Lancet. 2020;395 (10225):709-733. doi:10.1016/S0140-6736(20)30045-3

10. Coresh J. Update on the burden of CKD. J Am Soc Nephrol. 2017;28 (4):1020-1022. doi:10.1681/ASN.2016121374

11. Sarnak MJ, Levey AS, Schoolwerth AC, et al. Kidney disease as a risk factor for development of cardiovascular disease: a statement from the American Heart Association Councils on Kidney in Cardiovascular Disease, High Blood Pressure Research, Clinical Cardiology, and Epidemiology and Prevention. Circulation. 2003;108(17):2154-2169. doi:10.1161/01.CIR.000009 5676.90936 .80

12. Di Angelantonio E, Chowdhury R, Sarwar N, et al. Chronic kidney disease and risk of major cardiovascular disease and non-vascular mortality: prospective population based cohort study. BMJ. 2010;341 (Sep30 1):c4986. doi:10.1136/bmj.c4986

13. Bommer J. Prevalence and socio-economic aspects of chronic kidney disease. Nephrol Dial Transplant. 2002;17(Suppl 11):8-12. doi:10.1093/ndt/17.suppl_11.8

14. Lee SJ, Chung CW. Health behaviors and risk factors associated with chronic kidney disease in Korean patients with diabetes: the Fourth Korean National Health and Nutritional Examination Survey. Asian Nurs Res (Korean Soc Nurs Sci). 2014;8(1):8-14. doi:10.1016/j. anr.2013.11.001 
15. De Francisco ALM, Fresnedo GF, Palomar R, et al. The renal benefits of a healthy lifestyle. Kidney Int. 2005;68:S2-S6. doi:10.1111/j.15231755.2005.09901.x

16. Biesenbach G, Grafinger $P$, Janko $O$, et al. Influence of cigarette-smoking on the progression of clinical diabetic nephropathy in type 2 diabetic patients. Clin Nephrol. 1997;48(3):146-150.

17. Sui Z, Wang J, Cabrera C, et al. Aetiology of chronic kidney disease and risk factors for disease progression in Chinese subjects: a single-centre retrospective study in Beijing. Nephrology (Carlton). 2020. doi:10.1111/nep.13714

18. Garcia-Garcia G, Jha V. Chronic kidney disease in disadvantaged populations. Indian J Nephrol. 2015;25(2):65-69. doi:10.4103/ 0971-4065.150078

19. WHO. Global Action Plan for the Prevention and Control of Noncommunicable Diseases 2013-2020. Geneva; 2013.

20. Levey AS, Coresh J, Balk E, et al. National Kidney Foundation practice guidelines for chronic kidney disease: evaluation, classification, and stratification. Ann Intern Med. 2003;139(2):137-147. doi:10.7326/0003-4819-139-2-200307150-00013

21. Khalil A, Abdalrahim M. Knowledge, attitudes, and practices towards prevention and early detection of chronic kidney disease. Int Nurs Rev. 2014;61(2):237-245. doi:10.1111/inr.12085

22. Levey AS, Coresh J, Bolton K, et al. K/DOQI clinical practice guidelines for chronic kidney disease: evaluation, classification, and stratification. Am J Kidney Dis. 2002;39(2 Suppl 1):S1-S266.

23. Damtie S, Biadgo B, Baynes HW, et al. Chronic Kidney Disease and Associated risk factors assessment among diabetes mellitus patients at A Tertiary Hospital, Northwest Ethiopia. Ethiop J Health Sci. 2018;28(6):691-700. doi:10.4314/ejhs.v28i6.3

24. National Institutes of Health, Epidemiology and Genomics research program diet history questionnaire. Available from: https://epi.grants. cancer.gov/dhq3/. Accessed May 1, 2020.

25. FMOH. National Guidelines for HIV/AIDS and Nutrition in Ethiopia. The Federal DemocraticRepublic of Ethiopia Ministry of Health; 2008.

26. Zipporah NW, Elizabeth K, Nicholas G, Dorcus M. Contribution of Amaranth Grain (A. Cruentus) on dietary intake and nutritional status of adults living with HIV in Mweiga, Nyeri, Kenya. J Basic Appl Sci Res. 2014;4(4).

27. Hu J, La Vecchia C, Negri E, et al. Dietary Vitamin C, E, and carotenoid intake and risk of renal cell carcinoma. Cancer Causes Control. 2009;20(8):1451-1458. doi:10.1007/s10552-009-9371-6

28. Odermatt A. The Western-style diet: a major risk factor for impaired kidney function and chronic kidney disease. Am J Physiol Renal Physiol. 2011;301(5):F919-F931. doi:10.1152/ajprenal.00068.2011

29. Faramawi MF, Johnson E, Fry MW, Sall M, Zhou Y. Consumption of different types of meat and the risk of renal cancer: meta-analysis of case-control studies. Cancer Causes Control. 2007;18:125-133. doi:10.1007/s10552-006-0104-9

30. Knight EL, Stampfer MJ, Hankinson SE, et al. The impact of protein intake on renal function decline in women with normal renal function or mild renal insufficiency. Ann Intern Med. 2003;138(6):460-467. doi:10.7326/0003-4819-138-6-200303180-00009

31. van den Berg E, Hospers FAP, Navis G, et al. Dietary acid load and rapid progression to end-stage renal disease of diabetic nephropathy in Westernized South Asian people. J Nephrol. 2010;24(1):11-17. doi:10.5301/JN.2010.5711

32. Goldfarb DS, Coe FL. Prevention of recurrent nephrolithiasis. Am Fam Physician. 1999;60(8):2269-2276.

33. Gopinath B, Harris DC, Flood VM, et al. Associations between dairy food consumption and chronic kidney disease in older adults. Sci Rep. 2016;6(1):39532. doi:10.1038/srep39532
34. Massy ZA, Stenvinkel P, Drueke TB. The role of oxidative stress in chronic kidney disease. Semin Dial. 2009;22(4):405-408. doi:10.11 11/j.1525-139X.2009.00590.x

35. Cachofeiro V, Goicochea M, de Vinuesa SG, et al. Oxidative stress and inflammation, a link between chronic kidney disease and cardiovascular disease. Kidney Int Suppl. 2008;74:S4-S9. doi:10.1038/ ki.2008.516

36. Adugna T, Merga H, Gudina EK. Impaired glomerular filtration rate, high grade albuminuria and associated factors among adult patients admitted to tertiary Hospital in Ethiopia. BMC Nephrol. 2018;19 (1):345. doi:10.1186/s12882-018-1153-5

37. Sumaili EK, Cohen EP, Zinga CV, et al. High prevalence of undiagnosed chronic kidney disease among at-risk population in Kinshasa, the Democratic Republic of Congo. BMC Nephrol. 2009;10(1):18. doi:10.1186/1471-2369-10-18

38. Adera H, Hailu W, Adane A, Tadesse A. Prevalence of anemia and its Associated Factors Among Chronic Kidney Disease patients at University Of Gondar Hospital, Northwest Ethiopia: a hospital-based cross sectional study. Int J Nephrol Renovasc Dis. 2019;12:219-228. doi:10.2147/IJNRD.S216010

39. Geletu AH, Teferra AS, Sisay MM, et al. Incidence and predictors of chronic kidney diseases among type 2 diabetes mellitus patients at St. Paul's Hospital, Addis Ababa, Ethiopia. BMC Res Notes. 2018;11 (1):532. doi:10.1186/s13104-018-3618-9

40. Junior G, Bentes A, Sousa V. Nutritional status evaluation and dietary habits among patients with chronic kidney disease in conservative treatment: a longitudinal study in Brazil. Nephrol Dial Transpl. 2018. doi:10.1093/ndt/gfx148

41. Crews DC, Bello AK, Saadi G. Burden, access, and disparities in kidney disease. Braz J Med Biol Res. 2019;52.

42. Asghari G, Momenan M, Yuzbashian E, et al. Dietary pattern and incidence of chronic kidney disease among adults: a population-based study. Nutr Metab. 2018;15(1):88. doi:10.1186/s12986-018-0322-7

43. Fiseha T, Kassim M, Yemane T. Chronic kidney disease and underdiagnosis of renal insufficiency among diabetic patients attending a hospital in Southern Ethiopia. BMC Nephrol. 2014;15(1):198. doi:10.1186/1471-2369-15-198

44. Chala G, Sisay T, Teshome Y. Chronic Kidney Disease And Associated risk factors among cardiovascular patients. Int J Nephrol Renovasc Dis. 2019;12:205-211. doi:10.2147/IJNRD.S223196

45. Stauffer ME, Fan T, Moura IC. Prevalence of anemia in chronic kidney disease in the United States. PLoS One. 2014;9(1):e84943. doi:10.1371/journal.pone.0084943

46. Wong MMY, Tu C, Li Y, et al. Anemia and iron deficiency among chronic kidney disease stages 3-5ND patients in the chronic kidney disease outcomes and practice patterns study: often unmeasured, variably treated. Clin Kidney J. 2019. doi:10.1093/ckj/sfz091

47. Sato Y, Mizuguchi T, Shigenaga S, Yoshikawa E, Chujo K, Minakuchi J, Kawashima S. Shortened red blood cell lifespan is related to the dose of erythropoiesis-stimulating agents requirement in patients on hemodialysis. Ther Apher Dial. 2012;16(6):522-528.

48. Babitt JL, Lin HY. Molecular mechanisms of hepcidin regulation: implications for the anemia of CKD. Am J Kidney Dis. 2010;55 (4):726-741. doi:10.1053/j.ajkd.2009.12.030

49. Rambod M, Kovesdy CP, Kalantar-Zadeh K. Combined high serum ferritin and low iron saturation in hemodialysis patients: the role of inflammation. Clin J Am Soc Nephrol. 2008;3(6):1691. doi:10.2215/ CJN.01070308

50. Tran L, Batech M, Rhee CM, et al. Serum phosphorus and association with anemia among a large diverse population with and without chronic kidney disease. Nephrol Dial Transplant. 2016;31 (4):636-645. doi:10.1093/ndt/gfv297 


\section{Publish your work in this journal}

The International Journal of Nephrology and Renovascular Disease is an international, peer-reviewed open-access journal focusing on the pathophysiology of the kidney and vascular supply. Epidemiology, screening, diagnosis, and treatment interventions are covered as well as basic

science, biochemical and immunological studies. The manuscript management system is completely online and includes a very quick and fair peer-review system, which is all easy to use. Visit http://www.dovepress.com/testimonials.php to read real quotes from published authors.

Submit your manuscript here: https://www.dovepress.com/international-journal-of-nephrology-and-renovascular-disease-journal 